\title{
Manipulation based on Fryette's Laws increases heart rate variability and muscle flexibility in subjects with headache.
}

\author{
Fabiana Forti Sakabe ${ }^{(1)}$, Daniel Iwai Sakabe(1), Gabriel Abreu Gonçalves ${ }^{(1)}$, Paloma Bernardelli dos Santos(1)
}

\begin{abstract}
Background: The sympathetic nervous system has a direct connection with the cervical spine, through the cervical ganglia, in the superior cervical ganglion; therefore the manipulation of the superior cervical spine could result on modifications of the heart rate variability (HRV). Objective: To evaluate the immediate effect of the manipulation based on the Fryette's laws of the superior cervical spinal (SCS) on HRV and posterior chain flexibility (PCF) in subjects with headache. Methods/Design: Twelve volunteers of both genders ( $23.8 \pm 2.8$ years), who had complaints of headache, participated in the study. Before and immediately after the HRV assessment, PCF was measured with the assistance of Wells and Dillon's Bench test. For this the volunteer remained seated with the spine erect, lower limbs extended and feet resting on the bench. Then it was requested maximum flexion of the trunk and measured with a ruler the achieved distance. The HRV was obtained by the cardiofrequencymeter Polar RS800 cx ${ }^{\circledR}$ and captured for continuous fifteen minutes with the volunteer resting in supine position. At five minutes of collection, with the volunteer in the same position, the SCS manipulation technique (Fryette's Laws) was performed bilaterally. The HRV assessment was performed in the time domain by the RMSSD index of RR intervals (Matlab For Windows version 6.1) in two different moments: before and after the manipulation. Statistical analysis consisted of the Kolmogorov-Smirnov test and paired t-test for comparison of pre and post manipulation variables $(p<0.05)$. Results: There was a significant increase $(p=0.004)$ in the RMSSD index after the manipulation (from $42.58 \pm 24.52$ ms before the manipulation to $51.25 \pm$ 27.55 ms ten minutes after manipulation). The PCF also increased significantly $(p=0.03)$ after the SCS manipulation (from $17.65 \pm 11.9$ $\mathrm{cm}$ to $21.40 \pm 13.8 \mathrm{~cm}$ ). Conclusions: The manipulation of SCS increased the HRV through the increase of the RMSSD index indicating a predominance of parasympathetic activity, and improved the PCF of the studied volunteers, also reduced signs and symptoms of headache.
\end{abstract}

Keywords: Manual Therapy; Musculoskeletal Manipulations; Cervical; Headache; Heart Rate.

\section{INTRODUCTION}

The heart rate is directly modulated by the sympathetic nervous system (SNS) through the paravertebral pathways releasing norepinephrine and generating tachycardia and a low variability, and the parasympathetic through the vagal pathways releasing acetylcholine and causing bradycardia and high variability. In these pathways the stimuli are inhibitory, the parasympathetic inhibits the sympathetic and vice versa. Heart rate variability ( $\mathrm{HRV}$ ) are oscillations in the beats between the RR intervals and can be calculated in an Echocardiogram ${ }^{(1)}$. According to the same author, it was verified the presence of a low HRV in subjects with cardiac and noncardiac diseases.

The SNS has a direct connection with the cervical spine, through the cervical ganglia, in the superior cervical ganglion, located in $\mathrm{C} 1$ and $\mathrm{C} 2$; its postganglionic fibers lead to the cardiopulmonary nerves following to the cardiac plexuses, reaching the heart and controlling their sympathetic activity ${ }^{(2,3)}$.

Osteopathy starts from the anatomical and physiological knowledge for dysfunctions, or loss of function, which leads to the identification of the cause of the problem from the view that the human being does not divide, is a unique being with its structures connected and interconnected, exerting a mechanism of integration between tension and compression and between physical/chemical force and energy ${ }^{(4)}$.

The manipulation of high velocity and low amplitude (HVLA) has the effect of stimulating the muscle spindle, causing a contraction and a relaxation soon after ${ }^{(5)}$. Spinal manipulation is effective in adults for: acute, subacute and chronic low back pain; migraine and cervicogenic headache ${ }^{(6)}$. 
Headache is a very common symptom and should be considered as a warning sign, whether it is a consequence of serious problems or not. It may be divided into primary or secondary headache. Primary headache: do not have their cause justified in usual clinical or laboratory tests. The main example is migraine, tension-type headache, cluster headache and others. Secondary headache: justifiable by clinical or laboratory tests. In these cases, the pain would be a consequence of an aggression to the organism, of general or neurological order. For example, muscular tension headaches associated with systemic infections, endocrine dysfunctions, intoxications; cerebral hemorrhage; meningitis; encephalitis; or central nervous system (CNS) lesions ${ }^{(7)}$.

Cervicogenic headache is caused by a dysfunction in the cervical spine, especially in the $\mathrm{C} 1, \mathrm{C} 2$ and $\mathrm{C} 3$ vertebrae. It may cause tightening, weight, burning and throbbing pain in the frontal, occipital, temporal or ocular region ${ }^{(8,9)}$.

Due to the possible influence of the cervical spine on the development or maintenance of headache and on the mechanical and neurological relationship of this region with the superior cervical ganglion, it can be hypothesized that the treatment of the cervical spine could interfere positively on the HRV and the symptoms of subjects with tension headache.

In view of the above, the objective of the study was to evaluate the effect of a session of manipulation of the superior cervical spine on the HRV, on the posterior chain flexibility and on the signs and symptoms of subjects with headache.

\section{METHODS}

This project was approved by the Research Ethics Committee of the Faculdades Integradas Einstein de Limeira with protocol number16-03/268. For participation in the study, all volunteers signed the free and informed consent form according to resolution 466/12 of the National Health Council. The evaluation and intervention were performed in the clinical school of physiotherapy of Faculdades Integradas Einstein de Limeira (FIEL).

Twelve volunteers of both genders, with a mean age of $23.8 \pm 2.8$ years, who presented complaints of headache participated in the study. Inclusion criteria were: age between 18 and 50 years, both genders and subjects with complaints of headache. The exclusion criteria were: the presence of spinal arthrodesis; positive Klein's test and Sharp-pursen test; patients with tumors; rhinitis and sinusitis; osteoporosis; systemic, neurological and rheumatologic diseases; being in continuous medical treatment for headache and depression; presenting temporomandibular disorders; being in orthodontic treatment.

It was used the following research instruments: the MIDAS Questionnaire (developed as a quick and effective method to identify cases of migraine and used to classify the frequency and intensity of headache), Cardiofrequecimeter - Polar
RS800cx ${ }^{\circledR}$ (used to assess the heart rate variability) and the Wells Bench (used to measure the posterior chain flexibility).

Before initiating the treatment protocol, all volunteers completed the MIDAS questionnaire (referring to the last month) to complement the diagnosis and calculate the intensity and frequency of the headache.

After completing the questionnaire, the flexibility of the posterior chain was evaluated using the Wells Bench. Therefore, the volunteer sat on the floor, with the lower limbs extended and the parallel feet resting on the bench. The researcher then asked the volunteer to tilt the torso forward and stretching his/her hands and pushing the bench's ruler as far as he/she could without flexing his knees. Reaching maximum amplitude, the researcher noted the value in the ruler on the Wells Bench that the hand touched.

After completing the evaluations described above, the procedure for the collection of heart rate variability was started. The volunteer lay on a stretcher in the supine position and rested for 5 minutes. For evaluation of the autonomic modulation of heart rate, the volunteers' heart rate was recorded for 20 minutes without interruption, at rest in the supine position. This heart rate was obtained and calculated through electrocardiogram capture by the cardiofrequecimeter (Polar RS800cx ${ }^{\circledR}$ ). For the registry, it was initially performed the skin cleaning of the thoracic region with cotton soaked in $70 \%$ alcohol. Then, the collection belt was properly attached to the volunteer's chest below the nipple region.

One of the researchers remained holding the watch with the heart rate monitor at a distance of no more than one meter from the capture belt. The room where the collection was held had a temperature maintained at 22 and 24 degrees Celsius.

During the data collection, the volunteer was asked to stand still, breathing normally and without communicating with the researchers. At 10 minutes of collection, the intervention was performed through the application of the superior cervical spine manipulation. The technique used was the manipulation based on the Fryette's laws, which aims to non-specifically separate the articular facets in rotation, and it is always performed bilaterally.

The technique was performed by a certified professional in Osteopathy. The researcher remained standing closer to the head of the volunteer. The cephalic hand made contact with the opposite lateral region of the volunteer's skull leaving the sternocleidomastoid muscle (ECOM) between the third and fourth fingers. The caudal hand had global contact in the skull of the volunteer on the same side as the researcher was: fifth finger below the mental foramen region, fourth finger on the mental foramen region, third finger on the jaw, second finger on the zygomatic bone and first finger on the temporal bone scale. The researcher tilted the torso over the volunteer's head, leaving the forearms aligned on the axis of the volunteer's spine. He/she maintained neutral position of flexion-extension and placed the parameter of rotation towards the opposite 
side (70-80 degrees) and a small contralateral inclination. Then, it sought the motor barrier with a small movement of axial traction. When this barrier was found, Thrust technique was applied in a helical direction, increasing rotation and traction (Figure 1). The same procedure was repeated on the other side.

Data collection continued for ten minutes after the maneuver was completed to verify the immediate effect of manipulation on the HRV of the studied volunteers. Immediately after completion of the HRV collection, the posterior chain flexibility was reevaluated in the Wells Bench exactly as described previously. One month after the intervention, the volunteer received and responded again to the MIDAS questionnaire to verify the late effect of manipulation on the symptoms of headache.

\section{Data analysis}

The heart rate data were stored in the cardiofrequencimeter monitor in real time, and then transferred to a microcomputer to analyze the data obtained. The calculation of the HRV indices was performed in the Matlab for Windows version 6.1, and it was verified the RMSSD index of the RR intervals (time domain

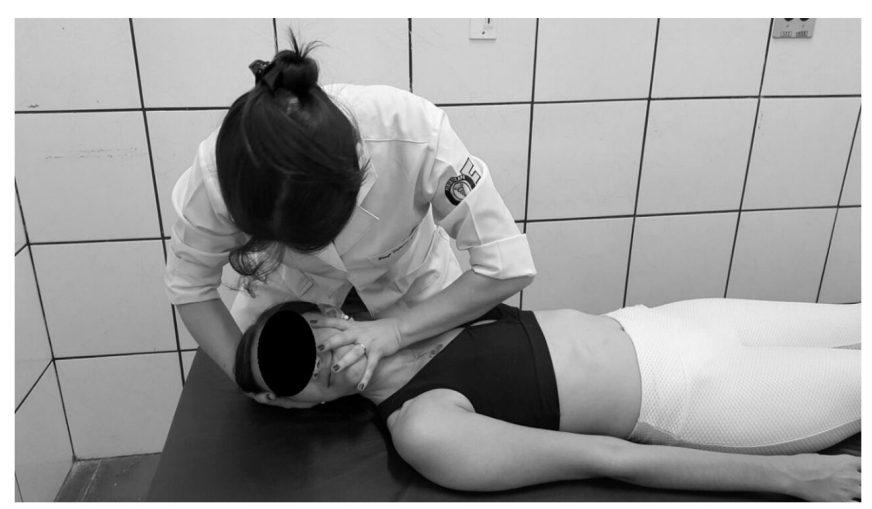

Figure 1 - Positioning of the volunteer and the researcher to perform the Fryette's Laws-based maneuver.

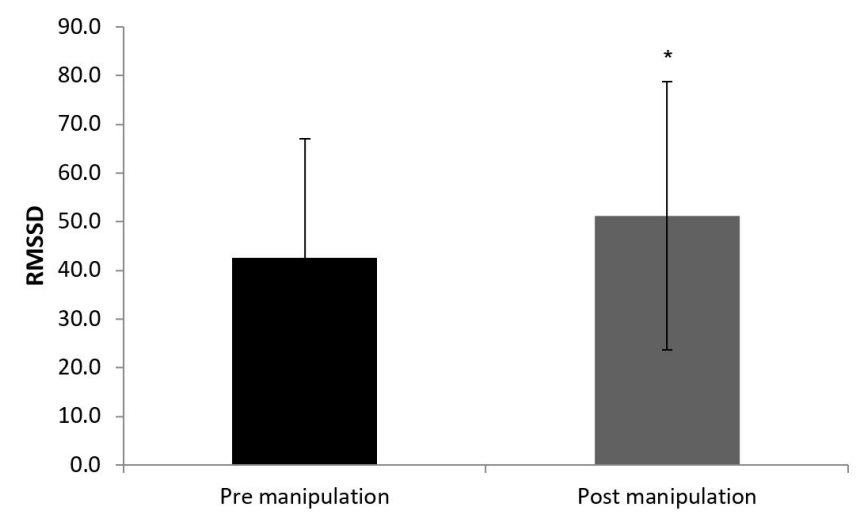

Figure 2 - Mean values \pm standard deviation of RMSSD of the RR intervals before (pre manipulation) and after (post manipulation) the superior cervical spine manipulation. analysis) representing the parasympathetic activity in heart rate control.

\section{RESULTS}

It can be seen in figure 2 that the HRV had a significant increase $(p=0.004)$ in the RMSSD index after manipulation (from $42.58 \pm 24.52 \mathrm{~ms}$ before the manipulation to $51.25 \pm 27.55 \mathrm{~ms}$ ten minutes after manipulation).

In figure 3 can be verified that posterior chain flexibility also increased significantly $(p=0.03)$ after superior cervical spine manipulation (from $17.65 \pm 11.9 \mathrm{~cm}$ to $21.40 \pm 13.8 \mathrm{~cm}$ ).

Figure 4 shows data from the MIDAS questionnaire on the signs and symptoms of headache. Significant reduction was observed in the three indices evaluated: total score $(p=0.01)$, number of crises $(p=0.04)$ and pain intensity (VAS) $(p=0.03)$, after a month of manipulation.

\section{DISCUSSION}

The autonomic nervous system (ANS) reflexively controls the cardiovascular system through the acetylcholine and adrenaline neurotransmitters, which when released in the

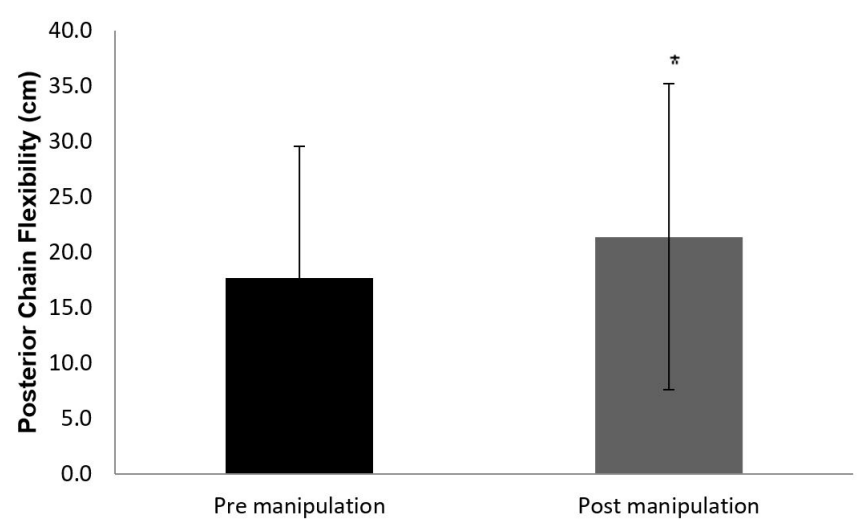

Figure 3 - Mean values \pm standard deviation of posterior chain flexibility before (pre manipulation) and after (post manipulation) the superior cervical spine manipulation.

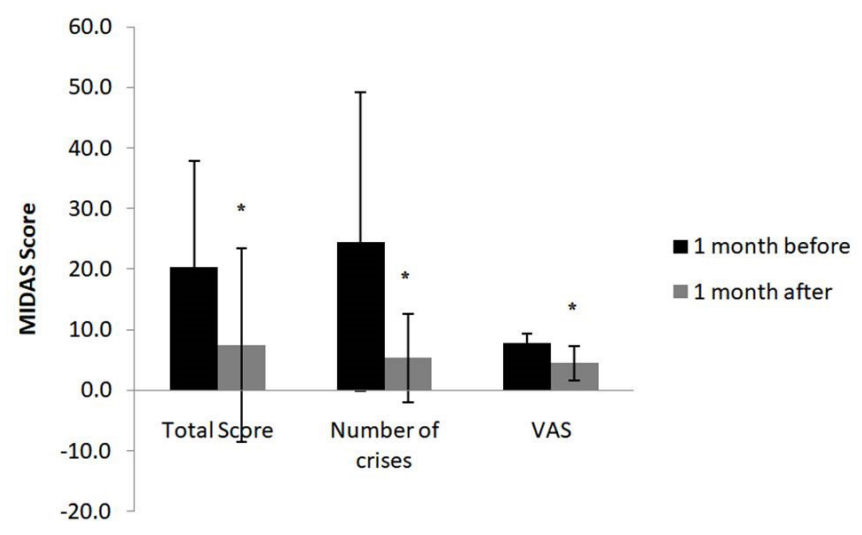

Figure 4-Mean values \pm standard deviation of MIDAS score before and after the cervical spine manipulation. 
heart, modify the contraction force of the myocardial fibers and the heart rate ${ }^{(10)}$. The sympathetic system has a direct relation with the cervical spine, through the cervical ganglia, being the superior cervical ganglion located in $\mathrm{C} 1$ and $\mathrm{C}^{(2,3)}$.

According to Sakabe et al. ${ }^{(11)}$ to modulate the variables of the cardiovascular system it is necessary the ANS and its sympathetic and parasympathetic efferent branches, increasing or decreasing in a variable way the heart rate and the heart beats. The sympathetic nervous system acts on the increase of the heart rate and on the decrease of the heart rate variability (HRV), unlike the parasympathetic nervous system that acts on the decrease of the heart rate and increase of its variability $^{(12)}$.

Fronchetti et al. ${ }^{(13)}$ declared that several techniques can be used to measure HRV. The magnitude of heart rate fluctuations may indicate autonomic dysfunction of the heart. Increased heart rate accompanied by low variability may reflect poor functional status. On the other hand, a reduction of the heart rate accompanied by a high vagal activity at rest, indicates a better condition of health and physical aptitude.

It has been demonstrated that cervical dysfunctions are related to different types of headache. For example, there is a restriction of cervical mobility in cervicogenic headache ${ }^{(14)}$. Thus, cervical hypomobility could affect the superior cervical ganglion and alter HRV.

According to Cerrato, Loza e Ugena ${ }^{(15)}$, when there is a somatic dysfunction in a medullary segment, there will be a medullary facilitation in the whole segment, maintained by the inflows that reach the medullary by the corresponding posterior horn. Consequently, there will be a state called local sympatheticotonia that can induce visceral changes and neurovascular disorders. According to the same authors, there is a close relationship between the osteopathic lesion (and its correction) and the changes in the neurovegetative balance. As the regulation of some homeostatic functions is mediated by the ANS, it is plausible that the relationship between the osteopathic lesion and its correction brings modifications in the regulation of these functions.

In high-velocity and low-amplitude (HVLA) manipulation, the impulse is usually provided through a short lever arm and controlling its speed, magnitude and direction of thrust ${ }^{(16)}$. Spence ${ }^{(17)}$ states that when a manipulation is made in the superior cervical vertebrae, a reflex stimulation is generated on the superior cervical ganglia from which the superior cardiac nerve emerges and, consequently, influences in the HRV.

According to Teixeira ${ }^{(10)}$ the osteopathic manipulative treatment may be able to modulate the vascular system and the ANS. However, the literature is scarce in studies associating hemodynamic and autonomic responses after manipulation.

In the present study, a significant increase of the RMSSD index of RR intervals was demonstrated after a session of manipulation of the superior cervical spine, indicating an improvement in $\mathrm{HRV}$, and a greater activation of the parasympathetic nervous system. This change in HRV could be explained because, according to Cerrato, Loza and Ugena ${ }^{(15)}$ when applying the OAA global manipulation bilaterally, the upper cervical ganglion on each side can be normalized. The same authors declared that the normalization of C0-C1-C2 and its relation to the $X$ cranial pair would affect the heart in a parasympathetic way, modifying its heart rate and the force of contraction. Another branch of the superior cervical ganglion is the superior cardiac nerve, which could also affect the heart and consequently the PA.

The results of the present study corroborate with the study of Teixeira ${ }^{(10)}$, in which compared the effects of the manipulative treatment in vascular function (flow-mediated dilation - FMD) and autonomic (heart rate variability) in cardiac. It was verified an increase in FMD and vagal indices immediately after the technique (RMSSD, SDNN and SD1) and after 10 minutes of follow up of maintenance of the increased vagal.

Caporossi ${ }^{(18)}$ states that there is an association of some homeostatic functions with changes in the occipitocervical fusion. In the presence of certain lesions of this segment, there may be vegetative hypertonia, and sympatheticotonia due to an inhibition of the $X$ cranial nerve (vagus nerve), or a parasympathotonia due to an opposite situation. Coster and Pollaris ${ }^{(19)}$ also verified a relation between $\mathrm{C} 0-\mathrm{C} 1-\mathrm{C} 2$ and $\mathrm{X}$ cranial nerve (vagus nerve).

In the study of Barreira ${ }^{(20)}$ was evaluated the immediate effect of manipulation on the HRV in different positions. Seven male, healthy and university students, were submitted to two types of intervention: the HVLA manipulation in cervical ( $\mathrm{C} 2$ to $\mathrm{C} 7$ ) and thoracic (T1 to T4) spine, and the Sham Technique. It was verified that the proposed osteopathic treatment presented a significant increase only in the orthostatic position in both techniques. This result diverges from that found in the present study, since there was an increase in the analyzed variable even in the supine position. It is noteworthy that the manipulative techniques used in the studies are different.

According to Borges, Bortolazzo and Neto ${ }^{(21)}$ the HRV is a great marker for parasympathetic activity. The same authors declared that manipulation in the upper cervical spine stimulates the parasympathetic response through the vagus nerve. In control groups there were no significant differences.

Buggell and Hirano ${ }^{(22)}$ used the manipulative technique in $\mathrm{C} 1$ and $\mathrm{C} 2$ and another placebo in 24 healthy individuals without current neck or shoulder pain for HRV analysis. It was demonstrated, in the manipulated group, an increase in parasympathetic activity. These data are in agreement with the present study.

Thus, osteopathic intervention for cardiac and ANS diseases is based on cardiovascular and autonomic structures and functions. Somatic dysfunctions of the musculoskeletal system may lead to alteration of basal autonomic tome and influence 
the general visceral functioning. For the cardiovascular system, such dysfunctions in the region of the cervical and thoracic spine, responsible for the sympathetic innervation of the heart, and at the base of the skull (passage of cardiac parasympathetic innervation) may negatively influence cardiovascular functioning.

The evaluation of muscle flexibility and stretching is of great importance for the study of the limitations of the joint range of motion $^{(23)}$. During joint manipulation, a high velocity and low amplitude thrust is applied by the therapist in the direction of restriction of the movement, up to the physiological limit of articulation. This impulse generates stretching of the joint capsule and muscles, aiming to release joint adhesions and restore the range of physiological joint movement. There is, by reflex, inhibition of the monoarticular muscles, which contributes to the restoration of movement ${ }^{(24)}$.

The results of the present study demonstrated an improvement in the PCF after SCS manipulation. There is a direct anatomical relationship between the dura mater of the superior cervical spine, the posterior cranial fossa and the ventral rami of the nerves that are connected to $\mathrm{C} 1-\mathrm{C} 3$, and therefore may be a possible source of headache if there is joint dysfunction between these vertebral segments.

Headache of the cervicogenic type originates from the dysfunction of the articular facets of the cervical spine, caused by irritation of the cerebral nerve or posterior sympathetic nerve. According to Zhou, Hud-Shakoor and Hennessey ${ }^{(9)}$ after anesthetic infiltration in $\mathrm{C} 2$ there was a reduction in the symptoms of headache.

Manipulative therapy may be one of the treatments for this type of pathology ${ }^{(8)}$. It was verified in the present investigation, through the MIDAS questionnaire, that after a month of manipulation, there was a significant reduction of the symptoms of headache (total questionnaire score, frequency and intensity of headache). Almeida, Gomes and Gaullier(25) states that the approach in the joint by mobilization techniques enables a reestablishment of arthrokinematics and provides neuromodulatory effects for pain relief.

These results are probably due to the influence of joint manipulation on the function of the trigeminocervical nucleus, which is located at the level of the superior cervical spine. According to Otaño and Legal(26) the trigeminocervical nucleus is the neurological and anatomical junction between the skull and the spine, and is directly linked to the mechanisms of cranial, mandibular and cervical pain. The dysfunction of the joints between occiput and the C3 (upper cervical) vertebra is fully admitted as the origin of neck pain and headache.

\section{CONCLUSION}

In view of the results obtained, it can be concluded that the superior cervical manipulation increased the HRV through the increase of the RMSSD indexindicating a predominance of parasympathetic activity, improved the posterior chain flexibility and reduced the signs and symptoms of headache in the studied volunteers.

\section{Acknowledgments}

To the Research and Scientific Initiation Program (PAPIC) of the Faculdades Integradas Einstein de Limeira for the financial support in the development of this study.

\section{AUTHORS CONTRIBUTION}

F.F.S.: supervisor, manipulation procedure, writing of the article, data tabulation, statistical analysis; D.I.S.: co-supervisor, analysis of heart rate variability, writing of the article; G.A.G. and P.B.S.: Scientific Initiation students responsible for data collection and tabulation, writing of the article.

\section{CONFLICT OF INTEREST}

The authors declare that there was no conflict of interest.

\section{REFERENCES}

1. European society of cardiology the noth american society of pacing electrophysiology. Hart Rate Variability. Circulation.1996; 93:1043-1065.

2. Moore KL, Dalley AF. Anatomia Orientada Para a Clínica. 4. ed. Rio de Janeiro: Guanabara Koogan. 2001.

3. Machado ABM. Neuroanatomia Funcional. 2. ed. São Paulo: Atheneu. 2009.

4. Rezende RPDB, Gabriel A. Relações entre clínica e osteopatia. Rev Bras Clin Med, 2008; 6: 194-196.

5. González I. Impacto de Las Técnicas Manuales Usadas Enosteopatía Sobre Los Proprioceptores Musculares: revisión de la literatura científica, Osteopatía Científica. 2009; 4(2):70-5.

6. Bronfort G, Haas M, Evans R, Leininger B, Triano J. Effectiveness of manual therapies: the UK evidence report, BioMed Central. 2010; 18(3):1-33.

7. Speciali JG. Classificação das Cefaléias. Rev. FMRP-USP, Ribeirão Preto.1997; 30(4):421-427.

8. Teixeira MJ, Yeng LT, Altieri CE, Saito M. Cefaléia de origem cervical, Rev. Med. 2001; 80(2):297-306.

9. Zhou L, Shakoor ZH, Hennessey C, Ashkenazi A. Upper Cervical Facet Joint and Spind Rami Black for the Treatment of Cervicogenic Headache. American Headache Society, Woodbury. 2010; 50(4):657-663.

10. Teixeira FA. Efeitos do tratamento manipulativo osteopático na função cardiovascular em indivíduos saudáveis e com insuficiência cardíaca. 2015. 116p. Monografia (Pós graduação ciências e tecnologias em saúde) - Universidade de Brasília, Faculdade de Ceilândia, Brasília, 2015.

11. Sakabe DI, Catai AM, Neves VFC, Oliveira L, Silva de sá MF, Azevedo GD et al. Análise da modulação autonômica do coração durante condições de repouso em homens de meia-idade e mulheres pós-menopausa. Rev Bras Fisioter. 2004; 8(1): 89-95.

12. Sakabe D. I. Efeitos do treinamento físico sobre a modulação autonômica da frequência cardíaca e a capacidade aeróbia de mulheres pósmenopausa sem o uso e em uso de terapia hormonal. 2007. 179p. Tese (Doutorado em Ginecologia e Obstetrícia) - Faculdade de Medicina de Ribeirão Preto, Ribeirão Preto, 2007.

13. Fronchetti L, Nakamura F, Aguiar C, Oliveira F. Indicadores de regulação autonômica cardíaca em repouso e durante exercício progressivo. Aplicação do limiar de variabilidade da frequência cardíaca. Rev Port Cien Desp. 2006; 6(10): 21-28.

14. Zito G, Jull G, Story I. Clinical tests of musculoskeletal dysfunction in the diagnosis of cervicogenic headache. Manual Ther, 2006; 11:118-129, 2006. 
15. Cerrato ID, Loza EM, Ugena IMA. Modificaciones en la presión intraocular y la presión arterial en pacientes con diabetes mellitus tipo 1 tras la manipulación global occipucio-atlas-axis según Fryette. Ensayo clínico aleatorizado Osteopatía Científica. 2009; 4(1):3-12.

16. Pickar JG. Neurophysiological effects of spinal manipulation. The Spine Journal. 2002; 2: 357-371.

17. Spence AP. Anatomia humana básica. 2. Ed. São Paulo: Manole, 1991. $713 p$.

18. Caporossi R. Le systeme neurovegetatif et ses troubles functionnels. París: De Verlaque; 1995.

19. De Coster M, Pollaris A. Osteopatía visceral. Madrid: Paidotribo; 2001.

20. Barreira INO. Efeitos imediatos do tratamento manipulativo osteopático na função autonômica em jovens saudáveis. 2015. 35p. Monografia (Graduação em Fisioterapia) - Universidade de Brasília, Brasília, 2015.

21. Borges BLA, Bortolazzo GL, Neto HP. Effects of spinal manipulation and myofascial techniques on heart rate variability: A systematic review. Journal of Bodywork \& Movement Therapies, 2018 (in press).
22. Budgell B, Hirano F. Innocuous mechanical stimulation of the neck and alterations in heart-rate variability in healthy young adults, Autonomic Neuroscience: Basic and Clinical. 2001; 91:96-99.

23. Corbetta AR, Corbetta LR, Freiberger KR, Maciel VC, Navarro AC. Os testes de flexibilidade do banco de wells realizados em jovens no processo de recrutamento obrigatório demonstraram que a atividade física não influencia na flexibilidade muscular, Rev. Brasileira de Prescrição e Fisiologia do Exercício. 2008; 2(10):409-414.

24. Zatarin V, Bortolazzo GL. Efeitos da manipulação na articulação sacroilíaca e transição lombossacral sobre a flexibilidade da cadeia muscular posterior, Ter Man. 2012; 10(47):40-45.

25. Almeida RS, Gomes V, Gaullier CM, Dames KK, Nogueira LAC. Efeitos da terapia manual na cefaleia do tipo cervicogênica: uma proposta terapêutica, Acta. Fisiatr. 2014; 21(2):53-57.

26. Otaño L, Legal L. Modificaciones radiológicas delespacio entre eloccipucio yelcuerpodel atlas tras una manipulación global (OAA) de Fryette. Osteopatía científica. 2010; 5(2):38-46. 